PREPARED FOR THE U.S. DEPARTMENT OF ENERGY, UNDER CONTRACT DE-AC02-76CH03073

PPPL-3664

PPPL-3664

UC-70

Modeling of Spherical Torus Plasmas

for Liquid Lithium Wall Experiments

by

R. Kaita, S. Jardin, B. Jones, C. Kessel, R. Majeski, J. Spaleta

R. Woolley, L. Zakharov, B. Nelson, and M. Ulrickson

January 2002

NM|

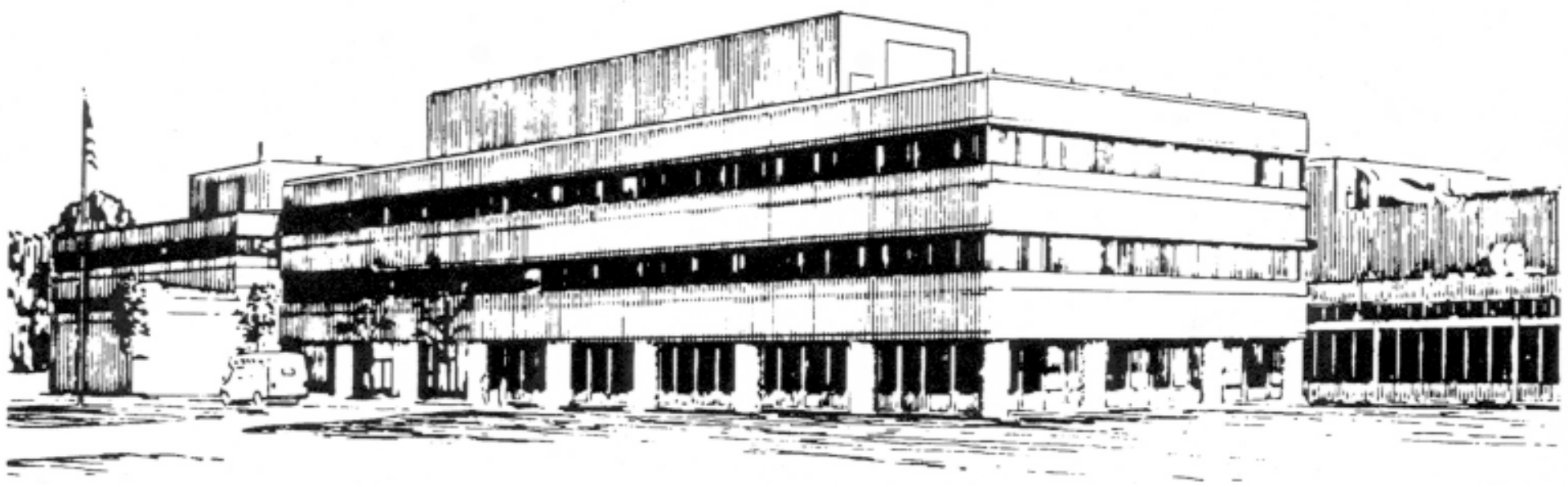

PRINCETON PLASMA PHYSICS LABORATORY PRINCETON UNIVERSITY, PRINCETON, NEW JERSEY 


\section{PPPL Reports Disclaimer}

This report was prepared as an account of work sponsored by an agency of the United States Government. Neither the United States Government nor any agency thereof, nor any of their employees, makes any warranty, express or implied, or assumes any legal liability or responsibility for the accuracy, completeness, or usefulness of any information, apparatus, product, or process disclosed, or represents that its use would not infringe privately owned rights. Reference herein to any specific commercial product, process, or service by trade name, trademark, manufacturer, or otherwise, does not necessarily constitute or imply its endorsement, recommendation, or favoring by the United States Government or any agency thereof. The views and opinions of authors expressed herein do not necessarily state or reflect those of the United States Government or any agency thereof.

\section{Availability}

This report is posted on the U.S. Department of Energy's Princeton Plasma Physics Laboratory Publications and Reports web site in Fiscal Year 2002. The home page for PPPL Reports and Publications is: http://www.pppl.gov/pub_report/

DOE and DOE Contractors can obtain copies of this report from:

U.S. Department of Energy

Office of Scientific and Technical Information

DOE Technical Information Services (DTIS)

P.O. Box 62

Oak Ridge, TN 37831

Telephone: (865) 576-8401

Fax: (865) 576-5728

Email: reports@adonis.osti.gov

This report is available to the general public from:

National Technical Information Service

U.S. Department of Commerce

5285 Port Royal Road

Springfield, VA 22161

Telephone: 1-800-553-6847 or

(703) 605-6000

Fax: (703) 321-8547

Internet: http://www.ntis.gov/ordering.htm 


\title{
Modeling of Spherical Torus Plasmas for Liquid Lithium Wall Experiments
}

\author{
R. Kaita, ${ }^{a}$ S. Jardin, ${ }^{a}$ B. Jones, ${ }^{a}$ C. Kessel,,${ }^{a}$ R. Majeski, ${ }^{a}$ J. Spaleta, ${ }^{a}$ R. Woolley, ${ }^{a}$ L. Zakharov, ${ }^{a}$ \\ B. Nelson, ${ }^{\mathrm{b}}$ and M. Ulrickson ${ }^{\mathrm{c}}$ \\ ${ }^{a}$ Princeton Plasma Physics Laboratory, Princeton University, Princeton NJ USA \\ ${ }^{b}$ Oak Ridge National Laboratory, Oak Ridge, TN USA \\ ${ }^{c}$ Sandia National Laboratories, Albuquerque, NM USA
}

\begin{abstract}
Liquid metal walls have the potential solve to first-wall problems for fusion reactors, such as heat load and erosion of dry walls, neutron damage and activation, and tritium inventory and breeding. In the near term, such walls can serve as the basis for schemes to stabilize magnetohydrodynamic (MHD) modes. Furthermore, the low recycling characteristics of lithium walls can be used for particle control. Liquid lithium experiments have already begun in the Current Drive eXperiment-Upgrade (CDX-U). Plasmas limited with a toroidally localized limiter have been investigated, and experiments with a fully toroidal lithium limiter are in progress. A liquid surface module (LSM) has been proposed for the National Spherical Torus Experiment (NSTX). In this larger ST, plasma currents are in excess of $1 \mathrm{MA}$ and a typical discharge radius is about $68 \mathrm{~cm}$. The primary motivation for the LSM is particle control, and options for mounting it on the horizontal midplane or in the divertor region are under consideration. A key consideration is the magnitude of the eddy currents at the location of a liquid lithium surface. During plasma start up and disruptions, the force due to such currents and the magnetic field can force a conducting liquid off of the surface behind it. The Tokamak Simulation Code (TSC) has been used to estimate the magnitude of this effect. This program is a two dimensional, time dependent, free boundary simulation code that solves the MHD equations for an axisymmetric toroidal plasma. From calculations that match actual ST equilibria, the eddy current densities can be determined at the locations of the liquid lithium. Initial results have shown that the effects could be significant, and ways of explicitly treating toroidally local structures are under investigation.
\end{abstract}

\section{INTRODUCTION}

Liquid walls offer many potential advantages over solid walls in the design of fusion energy systems.[1] Among them are the capability for high power density, which can eliminate thermal stress and wall erosion as limiting factors. This can also lead to smaller and lower cost components, such as chambers, shielding, vacuum vessels, and magnets. Other advantages are improved disruption survivability and reduced radiation damage in structural materials. Reduction in the volume of radioactive waste is also anticipated.

Liquid metal walls can result in improvements in plasma stability and confinement. These may permit plasmas with higher $\beta$, or ratio of plasma pressure to the pressure of the confining magnetic field. Exploration of the relationship between liquid metal walls and magnetohydrodynamic (MHD) instabilities has begun,[2,3] but many issues remain.

One of the features of a liquid lithium wall is its predicted effect on particle control. The benefits of a surface that has low recycling were shown with the "Deposition of Lithium by Laser Outside of Plasma" (DOLLOP) lithium wall conditioning experiments in the Tokamak Fusion Test Reactor (TFTR). [4] Effects on plasma density were also seen on the T-11M device, [5] where a Capillary Porous System (CPS) was used to form a "self-restoring" liquid lithium limiter surface.[6]

Experiments on the Current Drive Experiment-Upgrade (CDX-U) have recently begun with a fully toroidal lithium limiter.[7] The objective on CDX-U is to study auxiliary-heated discharges whose surface contact is primarily with a large-area liquid lithium limiter.

There are also plans to install a liquid surface module (LSM) on a large toroidal magnetic fusion device, such as the National Spherical Torus Experiment (NSTX) or Alcator C-Mod. A schematic of such a device for NSTX is shown in Fig. 1. The LSM is the thin rectangular structure on the right side of the figure. It spans the horizontal midplane of the vacuum vessel, and extends almost the full length of the space between the upper and lower passive stabilizer plates.

Studies have been performed of the hydrodynamics and MHD effects in liquid walls for various reactor concepts, including the spherical torus. They have already suggested certain special considerations for the ST. This confinement scheme has higher elongation compared to large aspect ratio devices (e. g., ARIES- 
$\mathrm{RS}[8]$ ), so the centrifugal force acting on the liquid as it moves poloidally along the wall is less. This force can be increased if the flow is caused to swirl in the toroidal direction, and it may actually improve its hydrodynamic stability.

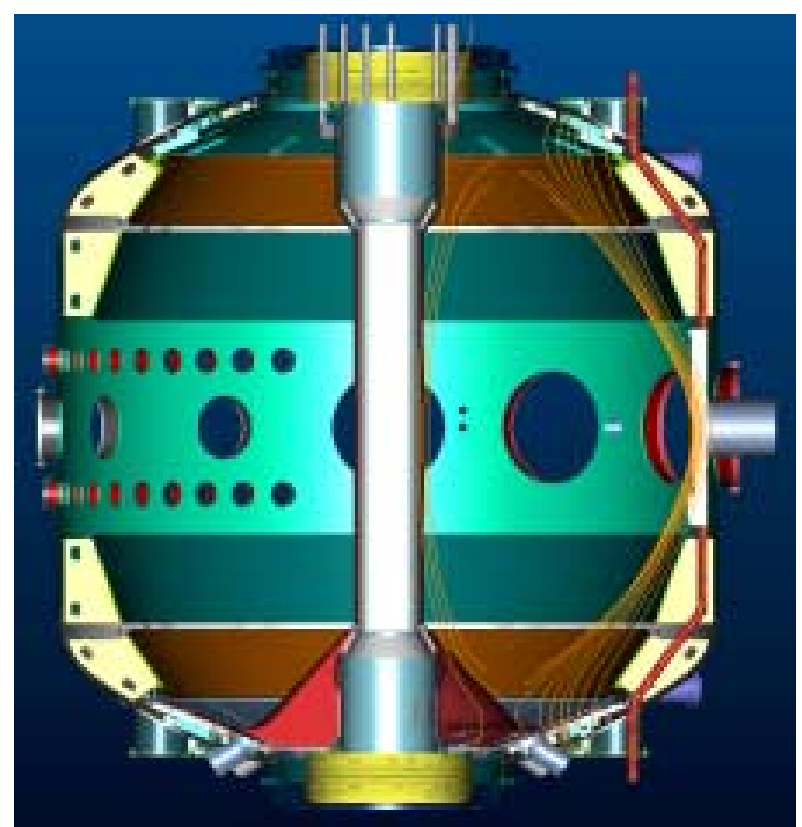

Fig.1. Cross section of NSTX with liquid lithium module. The field lines for a double null divertor configuration intersect the module on the midplane of the vacuum vessel.

Such investigations, however, have not included any dynamic calculations of the plasma itself. This paper identifies some of the issues that need to be addressed in such an integrated approach, and a first attempt at estimating the effects of an ST plasma on a liquid metal wall.

The Tokamak Simulation Code (TSC)[9] is the program that was used in this work. This is described in Section II. Two ST cases have been considered. The first involved the simulation of an NSTX plasma. Because measurements of the discharge parameters are available, this case provides a means of checking the validity of the TSC model. The second case focused on a burning plasma spherical torus (BP-ST) design. The two sets of simulations are compared in Section III. A summary of this preliminary study and issues to be addressed in future TSC are summarized in Section IV.

\section{DESCRIPTION OF THE TOKAMAK SIMULATION CODE}

The TSC is a program that calculates two-dimensional free boundary equilibria for fusion plasmas. It advances the magnetohydrodynamic (MHD) equations to determine the evolution of a magnetized toroidal plasma on a transport time scale.

The code evolves the magnetic field in a rectangular computational domain as it solves the Maxwell MHD equations for the plasma. Coupling to the circuit equations for the poloidal field coils occurs through the plasma boundary conditions.

The plasma model uses functional forms for the electron and ion thermal conductivities, the particle diffusion coefficients, and the plasma electrical resistivity. The transport mode is semi-empirical, in that it uses adjustable parameters to fit values from an experimental database. Reference [9] contains a detailed description of TSC.

\section{TSC SIMULATIONS OF NSTX AND BURNING PLASMA SPHERICAL TORUS DISCHARGES}

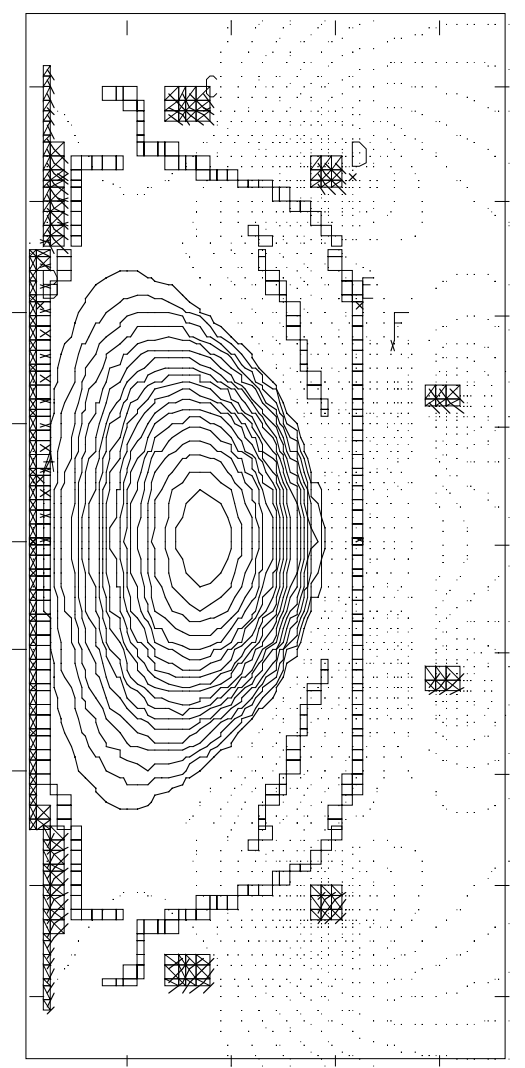

Fig.2. TSC simulation of 1 MA NSTX equilibrium 
The TSC program has been used simulate NSTX plasmas. Figure 2 shows some of the features of the model. It includes a vacuum vessel with $\mathrm{DC}$ breaks to permit different potentials for the inner and outer sections. This is a requirement for coaxial helicity injection,[10] which is a means for the noninductive initiation and sustainment of the plasma current.

The passive stabilizer shell, which is composed of curved copper plates above and below the midplane, is also in the model. The six rectangles outside of the vacuum vessel correspond to the poloidal field coils. The poloidal flux near the1 MA peak of the plasma current is shown inside the vacuum vessel.

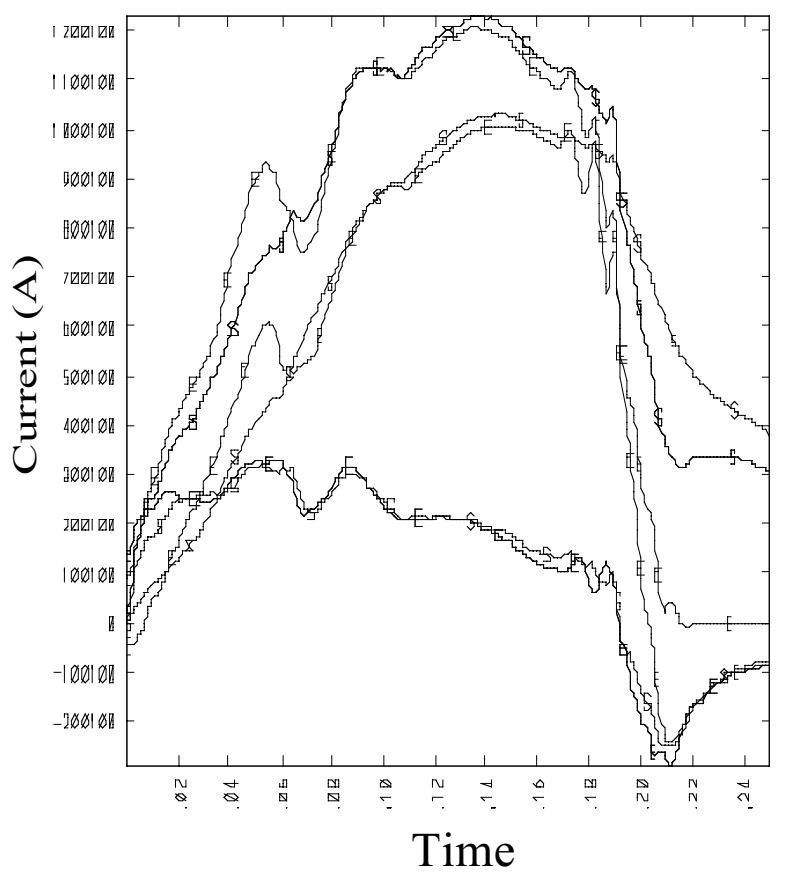

Fig.3. Comparison of TSC results with experimental measurements for 1 MA NSTX discharge

The TSC simulation of the time evolution of a typical 1 MA NSTX plasma is shown in Fig. 3. The uppermost curves show the sum of the currents in the plasma and the vacuum vessel. The plasma current alone is represented in the middle curves, and the vacuum vessel current is indicated in the lowermost curves. Each set of curves compares the TSC results with experiment, and the good agreement is reflected in how well they overlay.

A BP-ST discharge was also simulated with TSC. In this case, the plasma current was ramped up to its maximum value of $12 \mathrm{MA}$ in 4 seconds. The poloidal flux at the peak of the plasma current is plotted on a cross section of the vacuum vessel in Fig. 4.
As in Fig. 2, the rectangles outside of the vacuum vessel correspond to the eight poloidal field coils. Unlike NSTX, however, the vacuum vessel is continuous conductor, and there is no passive stabilizer shell.

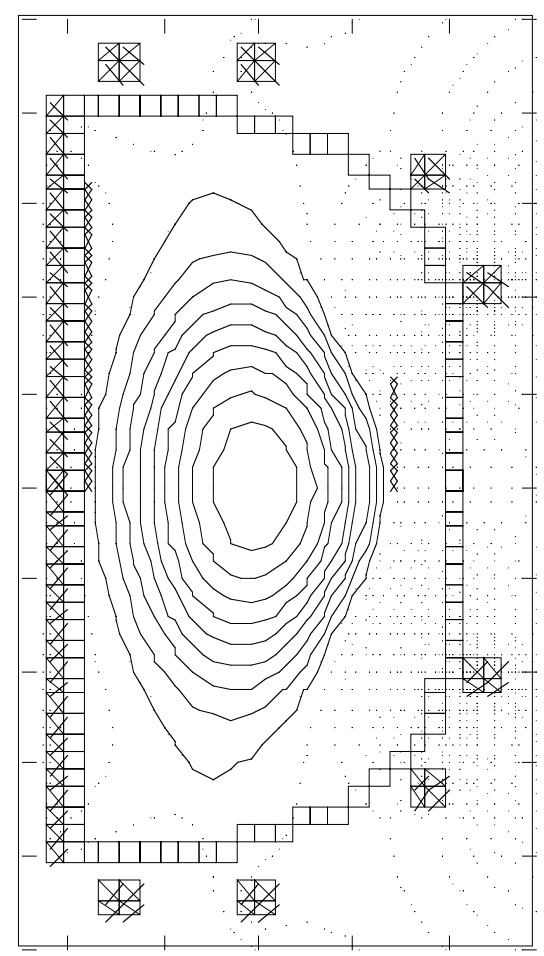

Fig.4. TSC simulation of 12 MA BP-ST equilibrium

As a first step in estimating the electromagnetic $(\boldsymbol{j} \boldsymbol{x} \boldsymbol{B})$ forces of plasmas on liquid lithium walls in the NSTX and BP-ST cases, the current densities induced at the location of a possible lithium surface were calculated with TSC. This was chosen to be at the vacuum vessel wall in the horizontal midplane of each device. The conductivity of lithium is similar to that of the stainless steel vacuum vessels typically assumed in the TSC simulations.

The current density determined for NSTX was about 4 X $10^{5} \mathrm{~A} / \mathrm{m}^{2}$. With a magnetic field at the vacuum vessel wall of about $0.15 \mathrm{~T}$, this translates into a force of about 6 newtons per square $\mathrm{cm}$. For the BP-ST, the value was approximately $3 \times 10^{4} \mathrm{~A} / \mathrm{m}^{2}$. The lower value reflects the slower current ramp of $3 \mathrm{MA} / \mathrm{s}$ in the latter case. The magnetic field at the vacuum vessel wall is about $0.8 \mathrm{~T}$, so that the corresponding force is 0.24 newtons per square $\mathrm{cm}$.

Although these forces appear to be modest, how they translate into the liquid lithium thicknesses and flow rates required for the MHD effects to be counteracted by the viscous force needs to be determined. This requires 
a simulation of the free fluid surface, and there is no model for it in TSC at this time.

\section{SUMMARY AND ISSUES FOR FUTURE TSC SIMULATIONS}

Spherical torus plasmas have been modeled with the TSC program. Calculations of NSTX plasmas show good agreement with experimental measurements. A useful model for an ST fusion reactor has also been provided with the BP-ST simulation. The TSC calculations have resulted in estimates of current densities at the vacuum vessel wall in the horizontal midplane of each machine.

The relationship between the current densities obtained from TSC and the requirements for liquid lithium flow is not yet known. The next step in determining this is to develop a code to model a free liquid lithium surface at the plasma boundary.

The TSC treats the region between the plasma and the wall as a high-resistivity fluid with uniform properties. The best solution for calculating the motion of the free lithium surface might be to take the electromagnetic loads from TSC and use these as input to another, more specialized code that can follow the motion of the lithium surface.

In contrast with the effects of a plasma on a liquid lithium wall, some of the consequences of such a wall on a plasma may be easier to simulate. The lithium surface is expected to be fully non-recycling. Its effects can be investigated with TSC by varying the particle confinement time and edge parameters. They would be changed in a manner consistent with the expected influence of the lithium, and this is planned for the next calculations with TSC.

\section{ACKNOWLEDGMENTS}

This work was supported by USDOE Contract No. DEAC02-76-CHO3073.

\section{REFERENCES}

[1] M. A. Abdou et al., Fus. Eng. Des. 54, 181-247 (2001)

[2] A. Y. Aydemir, Phys. Plasmas 8, 3411-3418 (2001)

[3] H. L. Rappaport, Phys. Plasmas 8, 3620-3629 (2001)

[4] D. K. Mansfield et al., Phys. Plasmas 3, 1892-1897 (1996)

[5] V. Lazarev et al., 26th EPS Conference on Controlled Fusion and Plasma Physics, Maastricht, The Netherlands, June 14-18 1999, P2.076 (1999)

[6] N. V. Antonov et al., J. Nucl. Mater. 241-243, 1190-1196 (1997)

[7] R. Majeski et al., these proceedings

[8] F. Najmabadi and the ARIES Team, Fus. Eng. Des. 38, 3-25

(1997)

[9] S. C. Jardin, N. Pomphrey, and J. DeLucia, J. Comput. Phys. 66, 481-507 (1986)

[10] R. Raman et al., Nucl. Fusion 41, 1081 (2001) 


\section{External Distribution}

Plasma Research Laboratory, Australian National University, Australia

Professor I.R. J ones, Flinders University, Australia

Professor J oão Canalle, Instituto de Fisica DEQ/IF - UERJ , Brazil

Mr. Gerson O. Ludwig, Instituto Nacional de Pesquisas, Brazil

Dr. P.H. Sakanaka, Instituto Fisica, Brazil

The Librarian, Culham Laboratory, England

Library, R61, Rutherford Appleton Laboratory, England

Mrs. S.A. Hutchinson, JET Library, England

Professor M.N. Bussac, Ecole Polytechnique, France

Librarian, Max-Planck-Institut für Plasmaphysik, Germany

J olan Moldvai, Reports Library, MTA KFKI-ATKI, Hungary

Dr. P. Kaw, Institute for Plasma Research, India

Ms. P.J . Pathak, Librarian, Insitute for Plasma Research, India

Ms. Clelia De Palo, Associazione EURATOM-ENEA, I taly

Dr. G. Grosso, Instituto di Fisica del Plasma, Italy

Librarian, Naka Fusion Research Establishment, J AERI, J apan

Library, Plasma Physics Laboratory, Kyoto University, J apan

Research Information Center, National Institute for Fusion Science, J apan

Dr. O. Mitarai, Kyushu Tokai University, J apan

Library, Academia Sinica, Institute of Plasma Physics, People's Republic of China

Shih-Tung Tsai, Institute of Physics, Chinese Academy of Sciences, People's Republic of China

Dr. S. Mirnov, TRINITI, Troitsk, Russian Federation, Russia

Dr. V.S. Strelkov, Kurchatov Institute, Russian Federation, Russia

Professor Peter Lukac, Katedra Fyziky Plazmy MFF UK, Mlynska dolina F-2, Komenskeho Univerzita, SK-842 15 Bratislava, Slovakia

Dr. G.S. Lee, Korea Basic Science Institute, South Korea

Mr. Dennis Bruggink, Fusion Library, University of Wisconsin, USA

Institute for Plasma Research, University of Maryland, USA

Librarian, Fusion Energy Division, Oak Ridge National Laboratory, USA

Librarian, Institute of Fusion Studies, University of Texas, USA

Librarian, Magnetic Fusion Program, Lawrence Livermore National Laboratory, USA

Library, General Atomics, USA

Plasma Physics Group, Fusion Energy Research Program, University of California at San Diego, USA

Plasma Physics Library, Columbia University, USA

Alkesh Punjabi, Center for Fusion Research and Training, Hampton University, USA

Dr. W.M. Stacey, Fusion Research Center, Georgia Institute of Technology, USA

Dr. J ohn Willis, U.S. Department of Energy, Office of Fusion Energy Sciences, USA

Mr. Paul H. Wright, Indianapolis, Indiana, USA 
The Princeton Plasma Physics Laboratory is operated by Princeton University under contract with the U.S. Department of Energy.

\author{
Information Services \\ Princeton Plasma Physics Laboratory \\ P.O. Box 451 \\ Princeton, NJ 08543
}

Phone: 609-243-2750

Fax: 609-243-2751

e-mail: pppl_info@pppl.gov

Internet Address: http://www.pppl.gov 